Tohoku J. Exp. Med., 1999, 189, 233-238

\title{
Analysis of the Retinal Edema of Full-Thickness Macular Holes by Scanning Laser Ophthalmoscopy and Optical Coherence Tomography
}

\author{
Yoshiko Akasaka, Shimpei Nishikawa and Makoto \\ TAMAI \\ Department of Ophthalmology, Tohoku University School of \\ Medicine, Sendai 980-8574
}

Akasaka, Y., Nishikawa, S. and Tamai, M. Analysis of the Retinal Edema of Full-Thickness Macular Holes by Scanning Laser Ophthalmoscopy and Optical Coherence Tomography. Tohoku J. Exp. Med., 1999, 189 (4), 233-238—The purpose of this study was to investigate the relationship between the dark area illuminated by scanning laser ophthalmoscopy (SLO) and cystic spaces around macular holes as shown by optical coherence tomography (OCT). SLO allows for two dimensional retinal examination, using short wave length $(514 \mathrm{~nm}$, argon) which is useful for the vitreoretinal surface and inner retina; red helium-neon laser $(633 \mathrm{~nm})$, which is capable of imaging deeper tissues; and infrared diode laser (780 $\mathrm{nm}$ ), for choroidal examination. OCT is analogous to ultrasound except that optical rather than acoustic reflectivity is measured. OCT can produce the crosssectional view of retina. Using SLO (helium-neon laser) and OCT, we examined 8 eyes with full-thickness macular holes. Eight normal eyes served as controls. Cystic spaces were in proportion to dark areas with statistical significance as shown by correlation analysis. Evaluation of the full-thickness macular holes by using both SLO and OCT is highly useful.__ dark area; macular hole; heliumneon laser; cystic space (C) 1999 Tohoku University Medical Press

Idiopathic full-thickness macular holes are a relatively common cause of unilateral central visual loss in the elderly people. Recent advances in the surgical treatment of macular holes have increased the ability to restore or prevent central visual loss. Macular holes have been diagnosed using several techniques. Scanning laser ophthalmoscopy (SLO) gives a more contrasted image of the macula than fundus photographs in macular diseases, but its use is limited to two-dimensional sections (Mainster et al. 1982). Optical coherence tomography $(\mathrm{OCT})$ is a new diagnostic imaging technique that produces high-resolution, cross-sectional views of the posterior regions of the eye (Swanson et al. 1993), and

Received September 26, 1999; revision accepted for publication November 30, 1999.

Address for reprints: Yoshiko Akasaka, M.D., Department of Ophthalmology, Tohoku

University School of Medicine, 1-1 Seiryomachi, Aoba-ku, Sendai 980-8574, Japan.

e-mail: AKASAKA@oph.med.tohoku.ac.jp 
successful tomographic imaging with OC'T has been reported (Hee et al. 1995). The macular hole is surrounded by a dark area when observed by SLO using helium-neon laser, and this dark area contains cystic spaces in the cross-sectional image of OCT as reported by Kishi and Takahashi (1998), who performed analysis of dark areas and cystic spaces. This paper, however, is the first report that dark areas, shown by SLO, are proportional to cystic spaces, shown by OCT, with statistical significance.

\section{Patients and Methods}

\section{Patients}

A total of 8 eyes from 7 patients were diagnosed idiopathic macular hole at Tohoku University Hospital. The patients studied had no coexisting retinal disease that could affect the functional status of the macula, and no evidence of aphakic or pseudophakic cystoid macular edema. Verbal informed consent was obtained from all patients. Examination findings of the study population are shown in Table 1. Eight eyes without retinal disease were also examined as controls.

\section{Methods}

Clinical diagnoses were established through indirect and contact lens slitlamp biomicroscopy, fundus photography, Amsler grid testing, and visual acuity testing. The macular hole was diagnosed and staged according to Gass' classification using slit lamp biomicroscopy with a 90 dioptre lens (Gass 1988, 1995). According to this classification, stage 3 holes are round with an elevated rim and a diameter of $400 \mu \mathrm{m}$ or more, and often have a prefoveolar pseudooperculum. The slit beam test (Watzke and Allen 1969) was also perfomed. SLO imaging and OCT imaging were conducted through a dilated pupil. With SLO (Rodenstock Instruments, Munich, Germany), the image of the fundus was

TABLE 1. Examination findings of patients with full-thickness macular holes

\begin{tabular}{ccccccccc}
\hline $\begin{array}{c}\text { Patient } \\
\text { no. }\end{array}$ & $\begin{array}{c}\text { Sex } / \\
\text { Age, years }\end{array}$ & Eye & VA & Stage & $\begin{array}{c}\text { DA } \\
(\mathrm{mm})\end{array}$ & $\begin{array}{c}\mathrm{CS} \\
(\mathrm{mm})\end{array}$ & $\begin{array}{c}\% \text { Diff } \\
(\%)\end{array}$ & $\begin{array}{c}\text { Hole } \\
(\mu \mathrm{m})\end{array}$ \\
\hline 1 & $\mathrm{M} / 63$ & $\mathrm{RE}$ & $20 / 40$ & 3 & 2.70 & 2.44 & 9.6 & 470 \\
2 & $\mathrm{~F} / 56$ & $\mathrm{LE}$ & $20 / 150$ & 3 & 2.10 & 1.90 & 9.5 & 560 \\
3 & $\mathrm{M} / 68$ & $\mathrm{RE}$ & $20 / 100$ & 3 & 2.50 & 2.40 & 4.0 & 850 \\
& & $\mathrm{LE}$ & $20 / 100$ & 3 & 2.30 & 2.32 & -0.9 & 470 \\
4 & $\mathrm{~F} / 63$ & $\mathrm{RE}$ & $20 / 200$ & 3 & 2.10 & 2.07 & 1.4 & 240 \\
5 & $\mathrm{~F} / 64$ & $\mathrm{LE}$ & $20 / 200$ & 3 & 2.64 & 2.48 & 6.1 & 330 \\
6 & $\mathrm{~F} / 63$ & $\mathrm{LE}$ & $20 / 150$ & 3 & 2.50 & 2.79 & -11.6 & 560 \\
7 & $\mathrm{M} / 69$ & $\mathrm{RE}$ & $20 / 150$ & 3 & 3.10 & 3.59 & -15.8 & 750 \\
\hline
\end{tabular}

VA, visual acuity ; DA, diameter of the dark area; CS, diameter of the cystic spaces; \%Diff, percent difference; RE, right eye; LE, left eye. 
$40 \times 40$ degrees. The rate of delivery was 25 images per second, and each image was made up of 380 lines of 568 pixels. The fundus was illuminated by a helium-neon (633 nm) laser. In OCT (OCT 2000, Carl Zeiss-Humphrey systems, Dublin, CA, USA) approximately $200 \mu \mathrm{W}$ of $830 \mathrm{~nm}$ probe light was shone on the fundus. The probe beam was delivered to the retina through a +78-diopter condensing lens and a pair of orthogonal scanning mirrors to provide lateral beam positioning in the eye. The beam was coincident with the observation path of the slit lamp so that the location of the OCT probe beam on the fundus could be visualized directly with an infrared-sensitive video camera. A B-mode crosssection of the retina is assembled from multiple A-scans by transversely scanning the probe beam across the retina. The images are displayed in false-color, where bright colors (red to white) correspond to regions of high relative optical reflectivity or backscatter, and dim colors (blue to black) represent areas of minimal or no relative reflectivity. A digital image processing algorithm is used to remove axial eye motion artifacts from the tomograph after data collection (Swanson et al. 1993).

\section{Quantitative analysis}

OCT depicts a horizontal-section acquired directly through the center of the fovea. Five-mm lengths of these images were scanned. The ends farthest from the fovea in the cystic spaces were measured using a scale and calculated proportionately to the scanning length $(5 \mathrm{~mm})$. The SLO-image was first calibrated by the prove beam of OCT, i.e., the OCT probe beam (scanning length, $5 \mathrm{~mm}$ ) reflected in the infrared-sensitive video camera was manually superimposed on the SLO-image. The transverse diameter of the dark area in SLO was measured manually, and calculated using a proportion to the scanning length $(5 \mathrm{~mm})$.

A software package (StatView for Macintosh, version 4.02; SAS Institute Inc., San Francisco, CA, USA) was used to perform Spearman's correlation analysis. A $p$ value of less than 0.05 was considered to be a statistical significant difference.

\section{Results}

The 8 eyes examined with both SLO and OCT had the following diagnosis which was confirmed by conventional clinical examination. The diameter of the dark area ranged from 2.10 to $3.10 \mathrm{~mm}(2.49 \pm 0.33 \mathrm{~mm})$. The diameter of the cystic spaces ranged from 1.90 to $3.59 \mathrm{~mm}(2.46 \pm 0.53 \mathrm{~mm})$. The diameter of the macular hole ranged from 240 to $850 \mu \mathrm{m}(529 \pm 201 \mu \mathrm{m})$ (Table 1). The SLO image of a macular hole consisted of a central bright round circle surrounded by a dark area as detected by the helium-neon laser (Fig. 1). The OCT image of case 5 was a stage 3 full-thickness macular hole as shown in Fig. 1. The retinal thickness increased to $470 \mu \mathrm{m}$ at the edge of the hole. Decreased reflectivity corresponding to these cystic changes was noted in the outer retinal layers sur- 

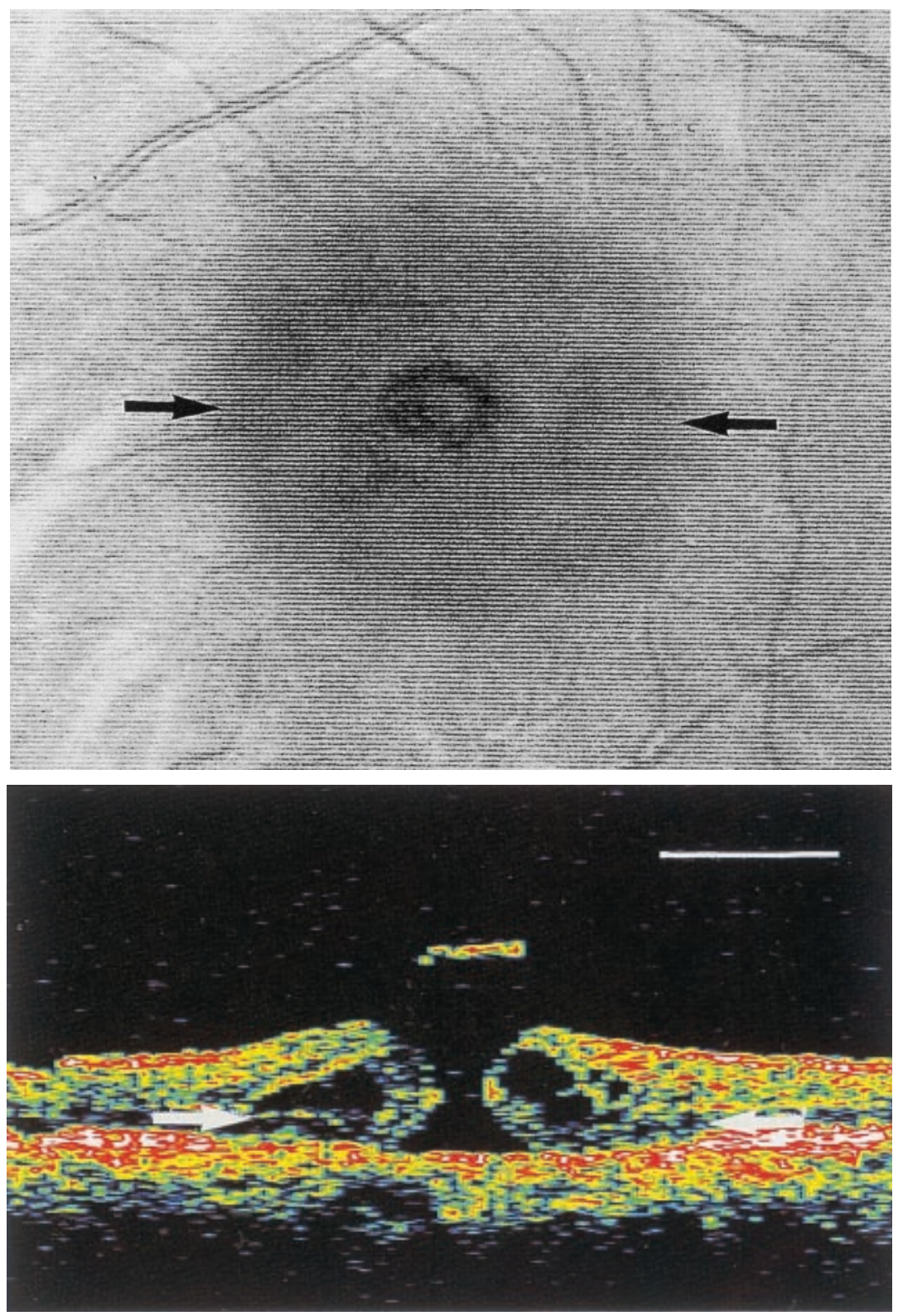

Fig. 1. Patient 5. (Top) Scanning laser ophthalmoscopic image. The round dark area (arrows), about $2.64 \mathrm{~mm}$ diameter, was examined by helium-neon laser. (Bottom) Optical coherence tomograph demonstrates a stage 3 hole with a large operculum anterior to the retina and a wide halo of retinal edema. The cystic spaces are $2.48 \mathrm{~mm}$ (arrows, bar $=1 \mathrm{~mm}$ ).

rounding the hole.

We compared cystic spaces with the dark areas around macular holes as shown by OCT. The diameters of the dark areas were in proportion to the size of the cystic spaces (Fig. 2), and showed statistical significance by Spearman's correlation analysis $\left(\mathrm{r}^{2}=0.79, p<0.05\right)$.

Eight normal eyes had a normal foveolar depression in OCT and no detectable dark areas in SLO using helium-neon laser. 


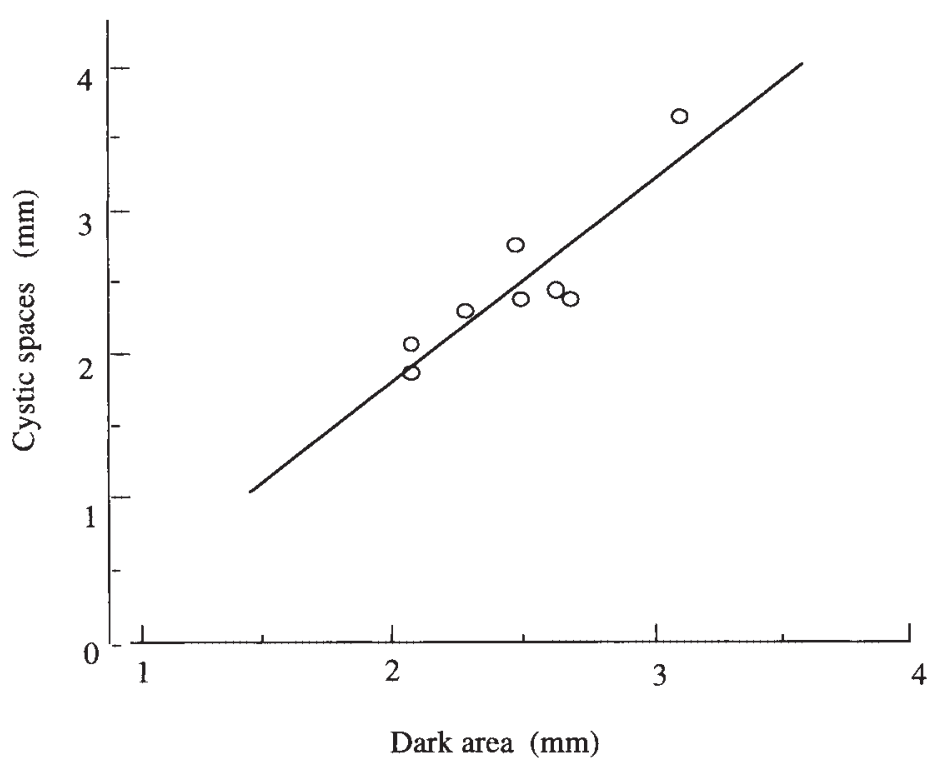

Fig. 2. Spearman's correlation analysis of dark area and cystic spaces. $\mathbf{r}^{2}=0.79$; $p<0.05$, showing statistical significance.

\section{Discussion}

In a normal eye, the central fovea comprises only the photoreceptor layer and the outer plexiform layer or Henle's fiber layer. It is surrounded by the bipolar cell layer, which is $350 \mu \mathrm{m}$ in diameter, and by the ganglion cell layer, which is $400 \mu \mathrm{m}$ in diameter. Macular holes are always round and have been reported to be from $350 \mu \mathrm{m}$ to $640 \mu \mathrm{m}$ in diameter (Chew and Sperduto 1999). In our examination, however, the diameter of the macular hole ranged from 240 to 850 $\mu \mathrm{m}$, although the median of hole diameters was similar to that of the above cited report. The outer margin of macular holes consists of foveolar retinal receptor cells by centrifugal displacement (Gass 1995). In our results, the dark area surrounding a macular hole ranged from $2.1 \mathrm{~mm}$ to $3.1 \mathrm{~mm}$ in diameter. The helium-neon laser has a long wavelength which penetrates the deeper retinal layer and allows visualization of the intraretinal structures. The origin of the dark area is unknown. In our experience, the dark area usually includes radiating striae (Kishi et al. 1995). This dark area contains cystic spaces as shown by the cross-sectional image of OCT (Kishi and Takahashi 1998). Postmortem examinations of eyes with idiopathic macular cysts have shown the cystic cavities to be present between Henle's fiber layer and the photoreceptor layer at the fovea (Guyer et al. 1990).

Macaca retinal morphology and macular OCT imaging correlate well, with alignment of areas of high and low reflectivity matching specific retinal and choroidal elements (Toth et al. 1997). By OCT we observed that the cystic spaces were situated between the outer plexiform layer and the outer nuclear layer. Macular holes are generally believed to be caused by tangential traction of the premacular vitreous cortex (Gass 1988; Guyer and Green 1993). 
It may be useful to employ both SLO and OCT for identifying, monitoring, and quantitatively assessing macular holes (Puliafito et al. 1995). We used both techniques for the examination of full-thickness macular holes. The results were statistically significant by correlation analysis and show that examination for macular holes using both SLO and OCT to be an accurate form of evaluation.

Based on the above findings using SLO and OCT on the same patients during the same visits for three-dimensional imaging of full-thickness macular holes, it is concluded that a combination of these two techniques is effective for evaluating preoperative features of retinal edema of full-thickness macular holes.

\section{References}

1) Chew, E.Y. \& Sperduto, R.D. (1999) Clinical course of macular holes. The eye disease case-control study. Arch. Ophthalmol., 117, 242-246.

2) Gass, J.D.M. (1988) Idiopathic senile macular hole: Its early stages and pathogenesis. Arch. Ophthalmol., 106, 629-639.

3) Gass, J.D.M. (1995) Reappraisal of biomicroscopic classification of stages of development of a macular hole. Am. J. Ophthalmol., 119, 752-759.

4) Guyer, D.R., Green, W.R. de Bustros, S. \& Fine, S.L. (1990) Histopathologic features of idiopathic macular holes and cysts. Ophthalmology, 97, 1045-1051.

5) Guyer, D.R. \& Green, W.R. (1993) Idiopathic macular holes and precursor lesions. Proceedings of the Symposium on Retina and Vitreous, New Orleans, LA, New York, Kugler Publications, 135-162.

6) Hee, M.R., Puliafito, C.A., Wong, C., Duker, J.S., Reichel, E., Schuman, J.S., Swanson, E.A. \& Fujimoto, J.G. (1995) Optical coherence tomography of macular holes. Ophthalmology, 102, 748-756.

7) Kishi, S., Kamei, Y. \& Shimizu, K. (1995) Tractional elevation of Henle's fiber layer in idiopathic macular holes. Am. J. Ophthalmol., 120, 486-496.

8) Kishi, S. \& Takahashi, H. (1998) Three-dimensional observation of idiopathic macular holes. Jpn. J. Clin. Ophthalmol., 52, 1463-1467.

9) Mainster, M.A., Timberlake, G.T., Webb, R.H. \& Hughes, G.W. (1982) Scanning laser ophthalmoscopy. Clinical applications. Ophthalmology, 89, 852-857.

10) Puliafito, C.A., Hee, M.R., Lin, C.P., Reichel, E., Schuman, J.S., Duker, J.S., Izatt, J.A., Swanson, E.A. \& Fujimoto, J.G. (1995) Imaging of macular diseases with optical coherence tomography. Ophthalmology, 102, 217-229.

11) Swanson, E.A., Izatt, J.A., Hee, M.R., Huang, D., Lin, C.P., Schuman, J.S., Puliafito, C.A. \& Fujimoto, J.G. (1993) In vivo retinal imaging by optical coherence tomography. Opt. Lett., 18, 1864-1869.

12) Toth, C.A., Narayan, D.G., Boppart, S.A., Hee, M.R., Fujimoto, J.G., Birngruber, R., Cain, C.P., DiCarlo, C.D. \& Roach, W.P. (1997) A comparison of retinal morphology viewed by optical coherence tomography and by light microscopy. Arch. Ophthalmol., 115, 1425-1427.

13) Watzke, R.C. \& Allen, L. (1969) Subjective slit beam sign for macular disease. Am. J. Ophthalmol., 68, 449-453. 